\title{
Two Rival Newly Fabricated Potentiometric Sensors to Enhance Selectivity Toward Cu(II) Ions
}

\author{
Gamal Abdel-Hafiz Mostafa ${ }^{1}$, Hazem Mohamed Abu Shawish ${ }^{2 *}$, Salman Mustafa Saadeh ${ }^{3}$, and Essam \\ Ezzeldin $^{1,4}$
}

${ }^{1}$ Department of Pharmaceutical Chemistry, College of Pharmacy, King Saud University, P.O. Box 2457, Riyadh 11451, Saudi Arabia

${ }^{2}$ Department of Chemistry, College of Sciences, Al-Aqsa University, Gaza, Palestine

${ }^{3}$ Department of Chemistry, Faculty of Science, The Islamic University, Gaza, Palestine

${ }^{4}$ Bioavailability Laboratory, Central laboratory, College of Pharmacy, King Saud, University, P.O. Box 2457, Riyadh 11451, Saudi Arabia

\section{*Corresponding author:}

email: hazemona1@yahoo.co.uk

Received: June 22, 2021

Accepted: August 26, 2021

DOI: $10.22146 /$ ijc. 66938

\begin{abstract}
Utilizing the well-known ability of Schiff base ligands to bind metal ions, two newly fabricated ligands, namely: 2-((2-hydroxybenzylidene)amino)benzoic acid (L1) and 2-(furan-2-ylmethyleneamino)phenol (L2) were employed to coordinate copper(II) $(\mathrm{Cu}(\mathrm{II}))$ producing the characteristically stable complexes that performed as the ionophores in the presently fabricated electrodes $A$ and $B$. Thus it was possible to build these electrodes that have attractive properties and expected behavior, namely, low detection limits: $2.32 \times 10^{-7}$ and $1.14 \times 10^{-6} \mathrm{M} \mathrm{Cu}(\mathrm{II})$, Nernstian slope of 29.13 and 30.85 $\mathrm{mV} /$ decade $\mathrm{Cu}(\mathrm{II})$, broad concentration ranges from $3.98 \times 10^{-7}-1.00 \times 10^{-2}$ and $1.52 \times$ $10^{-6}-1.00 \times 10^{-2} \mathrm{M}$ for sensors $A$ and $B$, respectively, as well as short response time (ca. 3$5 \mathrm{~s})$ with distinct selectivity toward $\mathrm{Cu}(\mathrm{II})$ over the other cations and applicability over the $\mathrm{pH}$ range 1.5-5.5 for miscellaneous samples: aqueous solutions, urine, and blood serum. Thus, these sensors surpass many others towards fulfilling the intended function of $\mathrm{Cu}(\mathrm{II})$ determination in various applications.
\end{abstract}

Keywords: Cu(II); ligands; modified carbon paste electrode; potentiometry

\section{- INTRODUCTION}

Copper is one of the trace metals essential to all organisms. Plants and animals need it even in small amounts for the proper function of the body. For example, in an average $70 \mathrm{~kg}$ human, the mass of copper element is $72 \mathrm{mg}$ and plays several crucially important biological roles: electron transfer systems in blue copper proteins; $\mathrm{O}_{2}$ storage and transport in hemocyanin and $\mathrm{Cu}$ transport proteins ceruloplasmin [1]. Copper is mainly obtained from food such as liver and nuts and whole grain products [2]. The Institute of Medicine recommended 10 mg per day as an upper intake [3-5]. Copper deficiency results in health problems such as anemia, growth retardation, heart failure, and gastrointestinal disturbances [6]. Despite being a moderately toxic element, exposure to high levels of copper is associated with gastrointestinal disturbances, Wilson disease, symptoms of hypertension, and dermatitis [7]. Compounds of copper are utilized in various applications such as fungicides, insecticides, and wood preservatives [8], which make liability for exposure for many people.

Advanced analytical methods requiring expensive instrumentation are reported to determine copper(II) $(\mathrm{Cu}(\mathrm{II}))$ in various matrices at trace levels. These methods are neutron activation analysis [9], X-ray fluorescence [10], pulse polarography [11], inductively coupled plasma emission spectrophotometry (ICP-ES) [12], graphite furnace atomic absorption spectrophotometry (GF-AAS) [13], and flame atomic 
absorption spectrometry (FAAS) [14-16]. These analytical techniques are highly sensitive and selective, but they are quite expensive for developing countries. Also, they require well-qualified laboratory personnel and superior laboratory equipment. In addition, many of the reported methods have some shortcomings, such as the availability of sophisticated instruments, time-consuming operation, tedious work, multi-step processes for preconcentration of the analyte, and low selectivity with more serious interference problems [17].

The potentiometric analysis is the most often used analytical procedure for analysis for it is simple, many ligands have been used to determine $\mathrm{Cu}(\mathrm{II})$ [18-22]. However, these procedures have various limitations, such as a high limit of detection, a narrow range, or interferences from many ions. Modified carbon paste electrodes (MCPE) have attractive characteristic properties. Being chemically inert, robust, easy to prepare and use, having a renewable surface, low ohmic resistance, and no need for an internal solution give a stable response and are thus considered suitable for various applications [23-25]. Educated selection of constituents and their relative composition followed by relevant experiments to spot the combination that gives the best response will show up in the fabrication of new electrodes proven helpful for implementation in the intended chemical analysis. In this context, there are some reports on the determination of $\mathrm{Cu}(\mathrm{II})$ ions using carbon paste electrodes [18,26-28] that utilize different types of modifiers.

Schiff base ligands are readily prepared by condensation of aldehydes and primary amines. These ligands can coordinate many different metals and stabilize them in various oxidation states [29]. Multidentate Schiff bases have been widely used as ligands because they form highly stable coordination compounds with metal ions. These compounds have been found helpful as ionophores in metal sensors [30]. Tridentate ligands with $\mathrm{N}, \mathrm{N}$, and $\mathrm{O}$ donor atoms are considered hard Lewis bases. $\mathrm{Cu}(\mathrm{II})$ is considered a hard Lewis acid. Hard Lewis acids and bases have a preference in combination to form complexes. Metal complexes of tridentate ligands such as $\mathrm{N}-, \mathrm{N}$ - and $\mathrm{O}$-chelating ligands have received considerable attention for their attractive physicochemical properties. $\mathrm{Cu}(\mathrm{II})$ is notable for more flexible bonding to many ligands, especially non-symmetric polydentate ones.

In this contribution, two novel $\mathrm{Cu}(\mathrm{II})$-selective carbon paste electrodes based on tridentate Schiff base ligands that strongly bind its ions were fabricated and characterized. These electrodes have attractive properties of low detection limits, wide linear concentration ranges, fast response, selectivity, accuracy, and reproducibility proven in applications for $\mathrm{Cu}(\mathrm{II})$ determination in water, blood, and biological samples.

\section{- EXPERIMENTAL SECTION}

\section{Materials}

Chemicals of analytical grade were used and obtained from commercially available sources. 2aminophenol, 2-aminobenzoic acid, and furfuraldehyde were from Merck; salicylaldehyde from Riedel de Haen. Reagent grade graphite powder and the plasticizers: bis(2-ethylhexyl) adipate (DOA), dioctyl phthalate (DOP), dibutyl phthalate (DBP), tris(2ethylhexyl) phosphate (DOPh), dioctyl sebacate (DOS), paraffin oils (P.O.), and all-metal salts such as chlorides, nitrates, and sulfates were from Aldrich. All materials were used with no further purification.

\section{Instrumentation}

Electromotive force (EMF) measurements were made using the following assembly:

$\mathrm{Hg}, \mathrm{Hg}_{2} \mathrm{Cl}_{2}$ (s), $\mathrm{KCl}$ (sat.) || sample solution | carbon paste electrode.

A digital millivoltmeter (SR-MUL-3800) was utilized for potential measurements, a digital $\mathrm{pH}$ meter (HANNA $\mathrm{pH} 211$ ) for $\mathrm{pH}$ measurements, and a saturated calomel electrode was used as a reference electrode to complete the electrochemical cell containing ion-selective electrodes. Elemental Analyzer EA 1110-CHNS CE Instrument was used in the analysis for carbon, hydrogen, and nitrogen. A PerkinElmer FTIR spectrophotometer using a $\mathrm{KBr}$ disk was used to record the infrared spectra of the materials in the range $4000-400 \mathrm{~cm}^{-1}$. 


\section{Procedure}

\section{Synthesis of ligands}

2-((2-Hydroxybenzylidene)amino)benzoic acid, as shown in Fig. 1, was prepared as described in the literature [31] by the reaction of equimolar amounts of 2aminobenzoic acid and salicylaldehyde in hot alcoholic solutions. Similarly, 2-(furan-2-ylmethyleneamino)phenol (Fig. 2) was prepared from furfuraldehyde and 2aminophenol [32]. The mixtures were allowed to stand and cool. The red-orange solids that separated were filtered off, washed with little amounts of the solvent, and dried. The product ligands were confirmed by the infrared and NMR spectra of both compounds. IR spectrum of 2((2-hydroxybenzylidene)amino)benzoic acid: $3233 \mathrm{~cm}^{-1}$ (br, OH str), $1616 \mathrm{~cm}^{-1}$ (C=N str). NMR spectrum: 6.497.89 ppm (aromatic protons, $8.86 \mathrm{ppm}$ (azomethine protons), $10.27 \mathrm{ppm}(\mathrm{OH}), 10.71 \mathrm{ppm}$ (COOH). IR spectrum of 2-(furan-2-ylmethyleneamino)phenol: 3405 $\mathrm{cm}^{-1}$ (br, OH str), $1643 \mathrm{~cm}^{-1}$ for $\mathrm{v}(\mathrm{C}=\mathrm{N}), 1018 \mathrm{~cm}^{-1}$ (s, CO str). NMR spectrum: 5.0 ppm (s, OH), 6.1-7.7 ppm (m, aromatic) $8.45 \mathrm{ppm}$ (s, CH imine).

\section{Preparation of modified carbon paste electrode}

A previously reported method [33] was followed to prepare the modified carbon paste electrode. First, weighed amounts of the ionophore, high purity graphite, and plasticizers, as shown in Table 1, were thoroughly mixed in plastic Petri dishes to make a uniformly wet

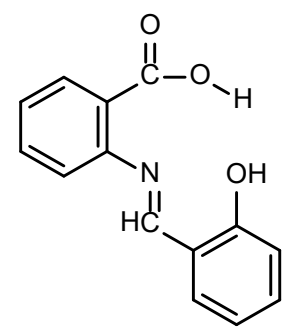

Fig 1. The chemical structure of ligand 1 [2-((2hydroxybenzylidene)amino)benzoic acid]

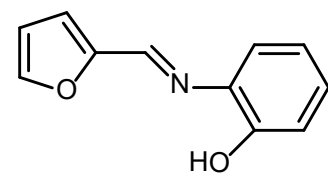

Fig 2. The chemical structure of ligand 2 [2-(furan-2ylmethyleneamino)phenol] paste used in constructing the sensors. Next, a $1 \mathrm{~mL}$ polypropylene syringe (3 $\mathrm{mm}$ i.d.) was used as the electrode body, and its tip was cut off. The paste was packed in, and a copper wire was used for electrical contact with the carbon paste. The paste was squeezed to expel some of it out. The expelled amount was scraped to expose a fresh mass at the tip of the electrode. The tip was polished on smooth paper to make a shiny surface. The plunger of the syringe was forced in to expel the paste at the tip. The expelled amount was scraped to expose a fresh mass there. Finally, the paste was polished on smooth paper to make a shiny surface. The electrode was then used directly for potentiometric measurements without pre-conditioning.

\section{Selectivity of the electrode}

The separate solution method (SSM) [23] and the modified separate solution method (MSSM) [34] were applied to check the potentiometric selectivity factors of the electrode. The SSM involves measuring the potential of a cell comprising a working electrode and a reference electrode in two separate solutions, one of the $\mathrm{Cu}(\mathrm{II})$ ions and the other of the interfering ion $(\mathrm{J})$, measured separately. The selectivity coefficient was calculated from the following equation:

$\log \mathrm{K}_{\mathrm{Cu}^{2+} \mathrm{J}^{\mathrm{z}}}^{\text {pot }}=\frac{\mathrm{E}_{\mathrm{J}-\mathrm{E}_{\mathrm{Cu}^{2+}}}}{\mathrm{S}}+\left(1-\frac{\mathrm{Z}_{\mathrm{Cu}^{2+}}}{\mathrm{Z}_{\mathrm{J}}}\right) \log \mathrm{a}_{\mathrm{Cu}^{2+}}$

where $E_{J}$ is the measured potential of the interfering ion, $\mathrm{S}$ is the slope of the calibration graph, $\mathrm{Z}_{\mathrm{Cu}^{2+}}$ is the charge on copper ion, and $Z_{\mathrm{J}}$ is the charge of the interfering species respectively.

The modified separate solution method (MSSM) involves measuring the potentiometric calibration curves of the primary (I) and interfering ions (J) and plotting the measured potential vs. the concentration of ionic species, the $\mathrm{Cu}$ (II) ion or the interfering ion. The potential corresponding to $1.0 \mathrm{M}$ concentration is obtained by extrapolation to zero potential. The selectivity coefficients for the studied electrode are calculated from the equation below:

$\log \mathrm{K}_{\mathrm{Cu}^{2+} \mathrm{J}^{\mathrm{Z+}}}^{\text {pot }}=\frac{\mathrm{E}_{\mathrm{J}}^{0}-\mathrm{E}_{\mathrm{Cu}^{2+}}^{0}}{\mathrm{~S}_{\mathrm{Cu}^{2+}}}$ 
Table 1. The paste compositions and the electrode characteristics of electrode A and electrode B

\begin{tabular}{|c|c|c|c|c|c|c|c|c|}
\hline \multirow{2}{*}{ No. } & \multicolumn{8}{|c|}{ Composition (\%) } \\
\hline & $\mathrm{L}$ & $\mathrm{g}$ & $\mathrm{p}$ & $S$ & D.R. (M) & L O D $(M)$ & R.S.D & $\mathrm{R}(\mathrm{s})$ \\
\hline \multicolumn{9}{|c|}{ Electrode A } \\
\hline \multicolumn{9}{|c|}{ Ligand 1} \\
\hline 1 & 0.2 & 50.4 & 49.4 (P.O.) & 30.89 & $7.45 \times 10^{-7}-1.00 \times 10^{-2}$ & $5.64 \times 10^{-7}$ & 0.87 & 4 \\
\hline 2 & 0.5 & 50.3 & 49.2 (P.O.) & 29.13 & $3.98 \times 10^{-7}-1.00 \times 10^{-2}$ & $2.32 \times 10^{-7}$ & 0.75 & 3 \\
\hline 3 & 1.0 & 50.0 & 49.0 (P.O.) & 29.27 & $1.00 \times 10^{-6}-1.00 \times 10^{-2}$ & $7.21 \times 10^{-7}$ & 0.81 & 3 \\
\hline 4 & 2.0 & 49.5 & 48.5 (P.O.) & 28.79 & $1.18 \times 10^{-6}-1.00 \times 10^{-2}$ & $1.10 \times 10^{-6}$ & 1.24 & 4 \\
\hline 5 & 3.0 & .490 & 48.0 (P.O.) & 28.09 & $1.31 \times 10^{-6}-1.00 \times 10^{-2}$ & $1.27 \times 10^{-6}$ & 1.38 & 5 \\
\hline 6 & 4.0 & 48.5 & 47.5 (P.O.) & 28.86 & $2.00 \times 10^{-6}-1.00 \times 10^{-2}$ & $1.38 \times 10^{-6}$ & 1.54 & 5 \\
\hline 7 & 5.0 & .480 & 47.0 (P.O.) & 30.34 & $3.25 \times 10^{-6}-1.00 \times 10^{-2}$ & $2.00 \times 10^{-6}$ & 1.43 & 5 \\
\hline 8 & 10.0 & 45.5 & 44.5 (P.O.) & 32.81 & $4.00 \times 10^{-6}-1.00 \times 10^{-2}$ & $2.00 \times 10^{-6}$ & 1.57 & 5 \\
\hline \multicolumn{9}{|c|}{ Effect of plasticizers } \\
\hline 9 & 0.5 & 50.3 & 49.2 (P.O.) & 29.13 & $3.98 \times 10^{-7}-1.00 \times 10^{-2}$ & $2.32 \times 10^{-7}$ & 0.75 & 3 \\
\hline 10 & 0.5 & 50.3 & 49.2 (DOP) & 28.54 & $3.81 \times 10^{-6}-1.00 \times 10^{-2}$ & $1.25 \times 10^{-6}$ & 1.22 & 5 \\
\hline 11 & 0.5 & 50.3 & 49.2 (DBP) & 34.73 & $7.53 \times 10^{-6}-1.00 \times 10^{-2}$ & $4.84 \times 10^{-6}$ & 1.35 & 5 \\
\hline 12 & 0.5 & 50.3 & $49.2(\mathrm{DOPh})$ & 34.49 & $1.67 \times 10^{-5}-1.00 \times 10^{-2}$ & $1.18 \times 10^{-5}$ & 1.77 & 4 \\
\hline 13 & 0.5 & 50.3 & 49.2 (DOS) & 35.18 & $4.13 \times 10^{-6}-1.00 \times 10^{-2}$ & $2.13 \times 10^{-6}$ & 0.98 & 5 \\
\hline 14 & 0.5 & 50.3 & $49.2(\mathrm{DOA})$ & 29.91 & $3.87 \times 10^{-6}-1.00 \times 10^{-2}$ & $2.86 \times 10^{-6}$ & 1.62 & 5 \\
\hline \multicolumn{9}{|c|}{ Electrode B } \\
\hline \multicolumn{9}{|c|}{ Ligand 2} \\
\hline 15 & 0.2 & 51.1 & 48.7 (P.O.) & 28.27 & $1.65 \times 10^{-6}-5.00 \times 10^{-2}$ & $1.16 \times 10^{-6}$ & 0.87 & 5 \\
\hline 16 & 0.5 & 50.5 & 49.0 (P.O.) & 30.85 & $1.52 \times 10^{-6}-1.00 \times 10^{-2}$ & $1.14 \times 10^{-6}$ & 1.21 & 3 \\
\hline 17 & 1.0 & 50.2 & .488 (P.O.) & 30.00 & $1.59 \times 10^{-6}-1.00 \times 10^{-2}$ & $1.37 \times 10^{-6}$ & 1.33 & 3 \\
\hline 18 & 2.0 & 49.7 & 48.3 (P.O.) & 30.47 & $1.85 \times 10^{-6}-1.00 \times 10^{-2}$ & $1.52 \times 10^{-6}$ & 1.17 & 4 \\
\hline 19 & 3.0 & .492 & .478 (P.O.) & 29.16 & $1.53 \times 10^{-6}-1.00 \times 10^{-2}$ & $1.19 \times 10^{-6}$ & 0.98 & 4 \\
\hline 20 & 4.0 & .478 & 47.3 (P.O.) & 28.63 & $4.00 \times 10^{-6}-1.00 \times 10^{-2}$ & $3.21 \times 10^{-6}$ & 0.63 & 5 \\
\hline 21 & 5.0 & .482 & .468 (P.O.) & 30.06 & $2.74 \times 10^{-6}-1.00 \times 10^{-2}$ & $1.55 \times 10^{-6}$ & 0.63 & 5 \\
\hline 22 & 10.0 & 45.7 & 44.3 (P.O.) & 31.75 & $1.28 \times 10^{-6}-1.00 \times 10^{-2}$ & $1.19 \times 10^{-6}$ & 0.63 & 5 \\
\hline \multicolumn{9}{|c|}{ Effect of plasticizers } \\
\hline 23 & 0.5 & 50.5 & 48.5 (P.O.) & .3085 & $1.52 \times 10^{-6}-1.00 \times 10^{-2}$ & $1.14 \times 10^{-6}$ & 1.21 & 3 \\
\hline 24 & 0.5 & 50.5 & 49.0 (DOP) & 31.14 & $2.37 \times 10^{-6}-1.00 \times 10^{-2}$ & $1.25 \times 10^{-6}$ & 1.72 & 4 \\
\hline 25 & 0.5 & 50.5 & 49.0 (DBP) & 31.43 & $2.91 \times 10^{-6}-1.00 \times 10^{-2}$ & $1.49 \times 10^{-6}$ & 1.67 & 5 \\
\hline 26 & 0.5 & 50.5 & $49.0(\mathrm{DOPh})$ & 31.69 & $2.67 \times 10^{-5}-1.00 \times 10^{-2}$ & $1.38 \times 10^{-5}$ & 1.13 & 4 \\
\hline 27 & 0.5 & 50.5 & 49.0 (DOS) & 30.63 & $3.32 \times 10^{-6}-1.00 \times 10^{-2}$ & $1.59 \times 10^{-6}$ & 1.14 & 5 \\
\hline 28 & 0.5 & 50.5 & $49.0(\mathrm{DOA})$ & 29.95 & $3.94 \times 10^{-6}-1.00 \times 10^{-2}$ & $2.32 \times 10^{-6}$ & 1.93 & 5 \\
\hline
\end{tabular}

L, Ligand; g, graphite; p, plasticizer S, slope (mV/decade); D.R., Dynamic range (M); LOD, low of detection (M); R, response time (s)

where $\log \mathrm{K}_{\mathrm{Cu}^{2+} \mathrm{J}^{\mathrm{z}}}^{\mathrm{zot}}$ selectivity coefficient; $\mathrm{E}_{\mathrm{J}}^{0}$ and $\mathrm{E}_{\mathrm{Cu}^{2+}}^{0}$ are values from the extrapolated to $\log (\mathrm{a})=0$ calibration curves for every interfering species and copper ion, and $\mathrm{S}_{\mathrm{Cu}^{2+}}$ is slope of the copper electrode.

\section{Determination of $\mathrm{Cu}(\mathrm{II})$ ion in water and biological samples}

Potentiometric titration method. Practically, a $25.0 \mathrm{~mL}$ sample of $1.0 \times 10^{-3} \mathrm{M} \mathrm{Cu(II)}$ solutions was potentiometrically titrated with $1.0 \times 10^{-2} \mathrm{M}$ EDTA. Plots of the potential versus concentration were constructed to get the curves representing the titrations performed. The endpoints were taken at the sharpest change in the slope of each titration curve.

Each titration was represented graphically by a plot 
of the measured potentials versus the corresponding concentrations to obtain the titration curve of that titration process. The endpoint is taken as the point that marks the sharpest change in the slope of that curve. This procedure is repeated for each titration.

Calibration graph method. This method involves the addition of known different amounts of copper ion ranging from $2.0 \times 10^{-7}-1.0 \times 10^{-2} \mathrm{M}$ to $50.0 \mathrm{~mL}$ of distilled water and measuring the resulting potential using the present sensors. The measured potentials were plotted versus the logarithms of the $\mathrm{Cu}$ (II) activity at these points representing the titration process to make the calibration curve or the calibration line. This line was used to determine the concentration of a copper ion in various sample solutions by matching the measured potential resulting from a particular sample to the concentration corresponding to it on the line.

The measured potentials were plotted versus the logarithms of the $\mathrm{Cu}$ (II) activity to build the calibration curve. The determination is made by matching the measured potential resulting from a particular sample to the corresponding concentration on the line.

Analysis of $\mathrm{Cu}$ (II) ion in biological fluids. Solutions of $1.96 \times 10^{-5}, 7.14 \times 10^{-5}$, and $1.66 \times 10^{-4} \mathrm{M} \mathrm{Cu}$ (II) made by spiking urine and copper samples ranging from $1.0 \mathrm{~mL}$ down to $0.1 \mathrm{~mL}$ with proper amounts of $\mathrm{Cu}(\mathrm{II})$, stirring for $5 \mathrm{~min}$, transferred to $50.0 \mathrm{~mL}$ volumetric flasks, diluted to volume and shaken to make homogeneous. The resulting solutions were analyzed for $\mathrm{Cu}$ (II) by the calibration curve method.

Analysis of water samples for $\mathbf{C u}(\mathrm{II})$ ion. There is no need for pretreatment of drinking water samples before analyzing $\mathrm{Cu}(\mathrm{II})$ using the present sensors. Therefore, $50.0 \mathrm{~mL}$ samples of water were analyzed following spiking of the samples with $\mathrm{Cu}$ (II) ranging from $5.0 \times 10^{-7}-5.0 \times$ $10^{-3} \mathrm{M} \mathrm{CuCl}_{2}$.

Potentiometric titration method. Titration of $20.0 \mathrm{~mL}$ samples of copper solutions versus $0.1 \mathrm{M}$ solution of EDTA was performed by measuring the potential against the volume of the titrant being added in small amounts. Then, the potential was plotted against the volume of the titrant. Finally, the endpoint was taken at the steepest change of the slope of the plot of the measured potential vs. volume of volume added EDTA solution.

\section{- RESULTS AND DISCUSSION}

Ion-selective electrodes (ISEs) are sensors commonly used to detect and determine certain ionic species. The ISEs behave as ion-exchangers where the analyte partitions into and out of the membrane or paste material, but the counter ion does not. The ionexchanger site is confined to its phase in the paste and does not partition into the sample solution. Charge separation and a phase boundary develop, leading to a local equilibration at this interface. The electrical potential difference across the sample-membrane phase boundary depends on the analyte concentrations at these sites. Efforts toward the construction of selective and sensitive sensors mainly depend on using effective ionophores or ligands for binding the intended ion. Logically, a ligand should selectively and strongly bind the intended ion, which stems from its structure and consequent properties, toward which extended research was made over the years to design suitable electrodes for various analytical purposes. Fabrication of new efficient electrodes for some objectives follows these guidelines [23-25].

\section{Characteristics of the Electrode}

A sensor is characterized by determining its sensitivity as well as its linear working range and selectivity coefficients. Essential features of a carbon paste electrode depend on its constituents, namely the properties of each component and its relative amount. To be specific: graphite, ligands, the plasticizer significantly affect the sensitivity and selectivity of the sensor.

\section{Response of the present electrodes to $\mathrm{Cu}(\mathrm{II})$ ions}

Ionophore-based ISEs are lipophilic host molecules with adequate polar functional groups for ion recognition at sites covalently anchored onto the backbone. They allow one to achieve a selectivity pattern following the thermodynamically stable but kinetically labile complexes with the analyte ion that forms in the 
membrane [35]. The selectivity depends on the structure of the ligands and their relative amount in the paste. Most ionophores are neutral and are highly lipophilic to be compatible with and strongly retained by the hydrophobic membrane phase resulting in operational sensor lifetimes ranging from weeks to years.

Lewis bases, also called ligands, are electron-pair donors that form coordinate bonds to metal ions. Two ligands were used in this work, namely: 2-((2hydroxybenzylidene)amino)benzoic acid (L1) and 2(furan-2-ylmethyleneamino)phenol (L2), which are shown in Fig. 1 and Fig. 2, respectively. They are tridentate ligands that form two stable chelate rings on complexation to a metal ion. However, the product complexes have slightly different stabilities due to differences in the size of the rings and the strength in electron donation of the donor pendant atoms in these ligands. For example, complexes of metal ions with L1 incorporate two 6-membered chelate rings, but those with L2 incorporate the slightly more stable 5 -membered rings. However, the furan moiety in ligand 2 is a hard Lewis base which is a strong donor, but $\mathrm{L} 1$ has the $\mathrm{COOH}$ moiety, which is a weaker donor and both ligands have the phenol moiety.

The potentiometric response of the present electrodes A and B were tested for different cations such

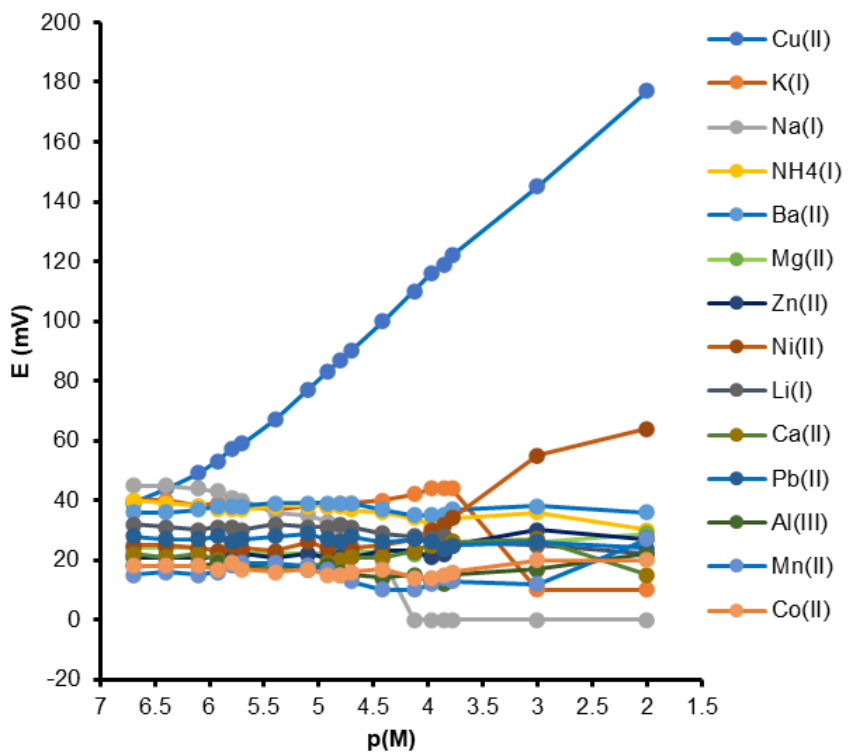

Fig 3. Potential response of various metal ions for sensor A as $\mathrm{Na}(\mathrm{I}), \mathrm{K}(\mathrm{I}), \mathrm{NH}_{4}(\mathrm{I}), \mathrm{Li}(\mathrm{I}), \mathrm{Ca}(\mathrm{II}), \mathrm{Zn}(\mathrm{II}), \mathrm{Ni}(\mathrm{II})$, $\mathrm{Mg}$ (II), $\mathrm{Ba}$ (II), $\mathrm{Mn}$ (II), $\mathrm{Cu}$ (II), $\mathrm{Co}(\mathrm{II}), \mathrm{Pb}$ (II), and $\mathrm{Al}(\mathrm{III})$ ions. The results of these tests are presented in Fig. 3 and Fig. 4. These figures show that the responses of the sensors are non-Nernstian for most of the tested cations. The results are shown in Fig. 3 and Fig. 4 for electrode 1 electrode 2, respectively. It can be seen from these figures that the responses of the sensors are non-Nernstian for most of the tested cations.

Notably, $\mathrm{Cu}$ (II) has the closest Nernstian response over a wide concentration range with a low detection limit, indicating that these ligands may be used as ionophores of copper(II) sensors.

$\mathrm{Cu}(\mathrm{II})$ is has a $\mathrm{d}^{9}$ electron configuration and adopts a tetragonally distorted structure in its octahedral complexes owing to the extra stability attained on this lowering the symmetry. This ion exemplifies such distortion. Moreover, this expected behavior can bond many ligands more strongly over other cations under the same conditions. This behavior amounts to selectivity to $\mathrm{Cu}$ (II) over other ions encountered in the solution. $\mathrm{Cu}$ (II) is considered a Lewis acid with intermediate strength that prefers to bind ligands of similar strength which means that copper(II) complex with L1 is more stable than L2. Thus, it is a case of two competing factors affecting the behavior of these ligands.

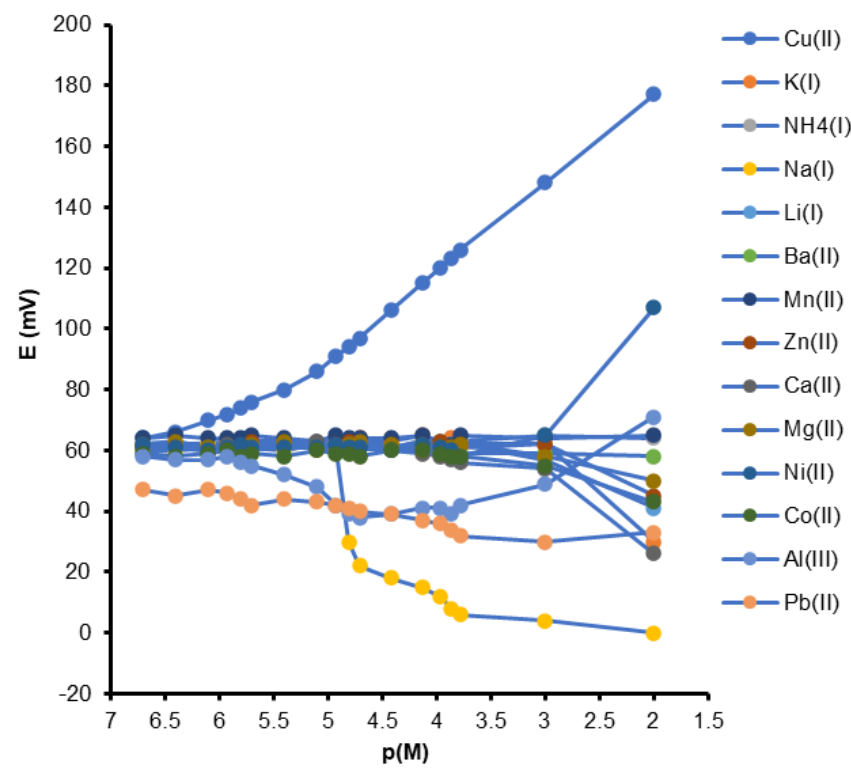

Fig 4. Potential response of various metal ions for sensor B 
First, we evaluated the net effect, which is the slightly better sensor characteristics fabricated using L1. The influence of the ligands L1 and L2 in the membrane composition as the ionophore for $\mathrm{Cu}$ (II) on the constructed electrodes' potential response was studied. The corresponding results are summarized in Table 1.

Electrodes comprising different percentages of each ionophore were prepared: 0.2, 0.5, 1.0, 2.0, 3.0, 4.0, 5.0, and $10 \%(\mathrm{w} / \mathrm{w})$. The following electrode characteristics: slopes, concentration ranges, detection limits, and response times of the calibration curves of the above electrodes were measured and shown in Table 1 . Inspection of the results showed that the electrodes comprising $0.5 \%$ of the ligands: L1 and L2 indicate the best response, closest to Nernstian behavior with remarkable selectivity for $\mathrm{Cu}(\mathrm{II})$, are electrodes $\# 2$ and \#16 in Table 1. Increasing the relative percent of L1 resulted in a notable deterioration in the detection limit, the slope, and the linear range of the electrode. This behavior is most probably due to some inhomogeneities and possible saturation of the paste [36]. Therefore, electrode \#2 was adopted in further applications. Similar behavior was noted on L2, where electrode \#16 comprising $0.5 \%$ as the ligand attained the lowest detection limit. However, further additions of L2 from $1.0-10 \%$ displayed somewhat similar sensitivity, slope, and linear range. Electrode \#16 of this ligand comprises the smallest amount of the ligand and gives the best response, so it was also adopted in further applications.

\section{Influence of the plasticizer}

When making carbon paste, one must keep in mind the mechanical stability of the paste and its active surface [37]. This function is supposed to be carried by the plasticizer, i.e., it is the main role of the plasticizer used in the preparation of the paste. In addition, it should provide high lipophilicity, a low tendency for exudation from the paste matrix, and the capacity to dissolve the substrate and other additives included in the paste. Good knowledge of the properties of a plasticizer is necessary for a suitable choice of one or more compatible with those of other components of the paste, especially the ionophore responsible for the primary function of the electrode [38]. Thus, a suitable plasticizer improves the response of the electrode. Based on the structurefunction relationship, the properties of a plasticizer stem from its chemical structure. It is possible to make the anticipation of a suitable plasticizer effectively improve the function of a certain ionophore. Plasticizers normally have low polarity based on their low dielectric constants. Choosing a plasticizer is based on the empirical basis where several plasticizers are tested and the one that best improves the electrode response is selected for further work, and applications of the electrode being fabricated. In this work six plasticizers were tested and listed below with the values of dielectric constants in parentheses, namely, DOS $(\varepsilon r=4.2)$, DOP $(\varepsilon r=5.1), \mathrm{DBP}(\varepsilon \mathrm{r}=6.4), \mathrm{DOPh}(\varepsilon \mathrm{r}=4.8), \mathrm{DOA}(\varepsilon \mathrm{r}=$ 3.9) and P.O. $(\varepsilon r=2.2)$ and the results obtained are shown in Table 1. Paraffin oil P.O. was found the most effective among these plasticizers. As the present ligands, L1 and L2 used as the ionophores, have characteristically low polarity, it is expected that a plasticizer with as low polarity as possible will work best with these ligands. This expectation was experimentally proven, as mentioned above.

\section{Effect of graphite/plasticizer ( $g / p)$ ratio}

Graphite and plasticizers are vital components of an ISE as their sensitivity and selectivity depend on the graphite to plasticizer ratio $\mathrm{g} / \mathrm{p}$. Therefore, electrodes comprising the following $\mathrm{g} / \mathrm{p}$ ratios: $0.75,0.90,1.00,1.02$, $1.05,1.20$, and 1.35 were tested to spot the one that marks the best response. Tests showed that pastes with $\mathrm{g} / \mathrm{p}$ more than 1.35 are "crumbly", indicating too much graphite, and those with ratios smaller than 0.75 resemble "peanut butter", i.e., contain more than enough of the plasticizer that makes the paste not workable. The best responses were attained with electrode $\mathrm{A}$ comprising $\mathrm{G} / \mathrm{P}=1.02$ and electrode $\mathrm{B}$ comprising $\mathrm{G} / \mathrm{P}$ $=1.03$, which reached the lowest detection limit and the closest Nernstian slope. This mixture contains a little more graphite necessary for efficient conductivity of the paste and enough plasticizer (paraffin oil) to provide the needed flexibility and workability and be sufficient to dissolve the constituents of the paste. The optimum physical properties of the paste were reached based on enabling high enough mobilities of all of its components. 
Therefore, this ratio was adopted in further developments of the present electrodes. Inspection of the results, collected in Table 1 indicates that electrodes \#2 composed of $0.5 \%$ L1, $51.0 \%$ graphite, and $48.5 \%$ P.O. and \#16 with the same composition but using L2 instead of L1 gave the best results and were adopted in more experiments toward the complete characterization of these electrodes.

\section{pH dependence}

The influence of the $\mathrm{pH}$ of the analyte solution on the potential of the present electrodes should be determined. It was studied for $1.0 \times 10^{-5}$ and $1.0 \times 10^{-3} \mathrm{M}$ $\mathrm{CuCl}_{2}$ solutions. The $\mathrm{pH}$ of the analyte solution affects the potential of the present electrodes. Therefore, this effect should be determined. Practically, it was studied in $1.0 \times$ $10^{-5}$ and $1.0 \times 10^{-3} \mathrm{M} \mathrm{CuCl}_{2}$ solutions. The solution's acidity was adjusted by adding small amounts of $(1 \mathrm{M})$ $\mathrm{HCl}$ or $\mathrm{NaOH}$, and the resulting potentials were measured. The results obtained using the two electrodes are practically linear over the $\mathrm{pH}$ range $1.5-5.5$, as seen from the representative plot in Fig. 5 for electrode A which collectively indicates that both electrodes satisfactorily behave over this range. Testing the electrodes in a solution with a $\mathrm{pH}$ lower than 1.5 was not performed as it is unlikely that $\mathrm{Cu}$ (II) analysis is requested in such strongly acidic solutions. In solutions having $\mathrm{pH}$ above 5.5, copper hydroxide precipitate as it has a relatively low solubility product. More copper hydroxide precipitates in solutions with higher $\mathrm{pH}$, leaving lower amounts and concentrations of copper ion and correspondingly lower measure potential.

\section{Response time, homogeneity, surface-renewal, and reproducibility}

The response time of an electrode depends on the membrane type and the interferents. Therefore, all relevant measurements must be made under the same experimental conditions when addressing this issue. It indicates how fast the unstirrable layer of sample adhering to the ISE membrane can be exchanged for a new layer noting that routine potentiometric measurements are associated with responses involving ion movements over nanometers at the phase boundary of the sample and the ion-selective membrane [39].
In the present work, the response time was measured by varying $\mathrm{Cu}$ (II) concentration over the range $4.0 \times 10^{-7}-4.0 \times 10^{-3} \mathrm{M}$ for electrode $\mathrm{A}$ and from $4.0 \times 10^{-6}-4.0 \times 10^{-3} \mathrm{M}$ for electrode $\mathrm{B}$. It was found that electrode $A$ reached equilibrium in about $3 \mathrm{~s}$, as shown in Fig. 6 for electrode A and was slightly longer (about $5 \mathrm{sec}$ ) for electrode B. The modified carbon paste electrodes are famous for their attractive possibility of renewal of the electrode surface whenever needed. The renewal is achieved by squeezing a little carbon paste out of the tube to expose a new amount which can be smoothed on a piece of weighing paper to a shiny surface [40]. The procedure requires making about $1.0 \mathrm{~g}$ of a paste with optimum

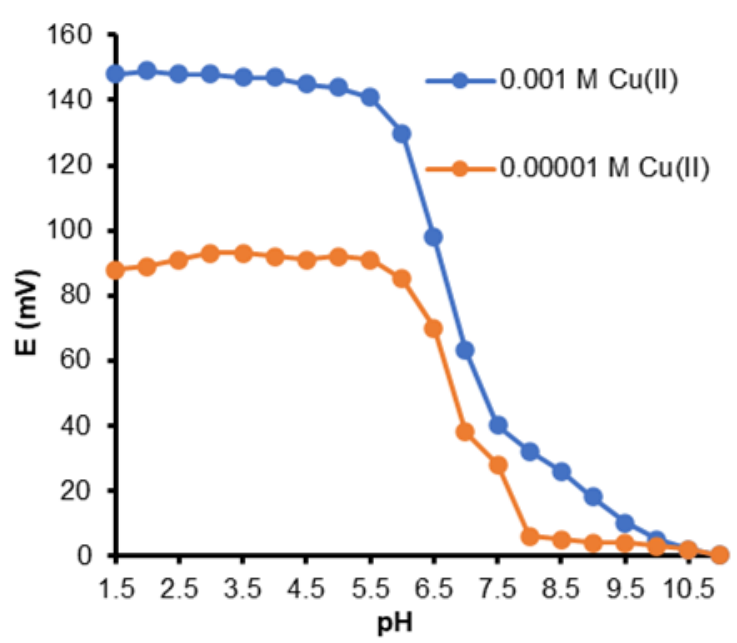

Fig 5. Effect of $\mathrm{pH}$ on potential response of electrode $\mathrm{A}$ using $1.0 \times 10^{-5}$ and $1.0 \times 10^{-3} \mathrm{M} \mathrm{Cu}(\mathrm{II})$ solutions

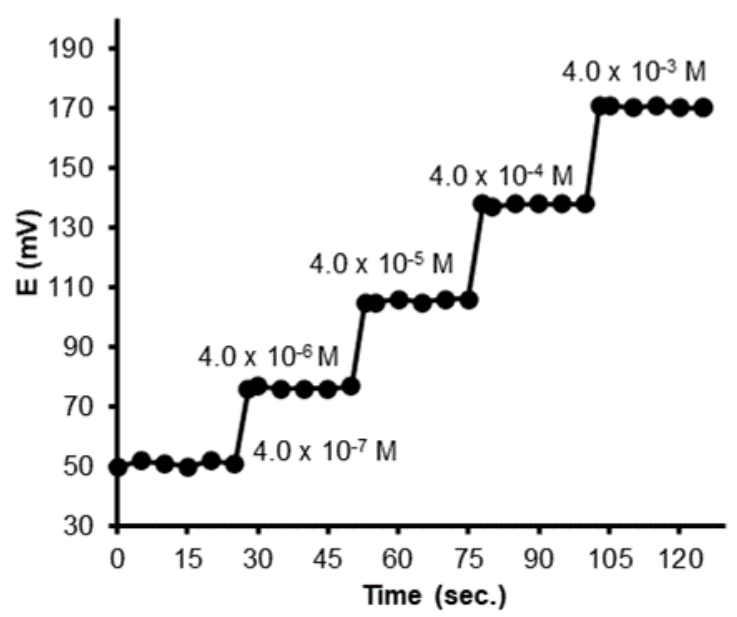

Fig 6. Dynamic responses of electrode A obtained by a successive increase of $\mathrm{Cu}(\mathrm{II})$ ion 
composition by intimately mixing its ingredients. This amount was suitable for use for over a month to get a stable response without any deterioration. However, more prolonged periods cause slight deterioration in the measured potentials, likely due to the evaporation of some of the incorporated plasticizers.

Homogeneity of the present electrodes was tested by applying the electrodes for measurement in a $1.0 \times 10^{-4} \mathrm{M}$ $\mathrm{Cu}$ (II) solution which was repeated seven times on a freshly exposed paste for each measurement as explained above. The average relative standard deviation (R.S.D.) for the proposed electrodes was $\sim 0.91$, which are reasonable values. However, after five times of use, it was noticed that the slope of the calibration graphs measured using electrode 1 decreased slightly from 29.13-26.95 $\mathrm{mV} /$ decade, and the slopes measured using electrode 2 decreased from $30.85-26.73 \mathrm{mV} /$ decade.

However, it was noticed that the slope of the calibration graphs measured using electrode 1 decreased slightly from $29.13-26.95 \mathrm{mV} /$ decade after five times of use. Similarly, the slopes measured using electrode 2 decreased from $30.85-26.73 \mathrm{mV} /$ decade. This decrease is likely due to surface contamination and memory effects and makes polishing the electrode necessary to expose a new fresh layer ready for use after each calibration. The standard deviation of five replicate measurements of the electromotive force (emf) is 1.23, 1.13 for electrodes $\mathrm{A}$ and $\mathrm{B}$ in $1.0 \times 10^{-6} \mathrm{M}$ solution, and $0.98,1.08$ in $1.0 \times 10^{-5} \mathrm{M}$ solution, respectively. These results indicate excellent repeatability of the potential response of the electrodes.

\section{Effect of temperature}

The thermal stability of an electrode must be checked and determined being one of its characteristics. Practically, this is done by constructing the calibration graphs of the electrodes in test solutions at different temperatures covering the range of $20-50{ }^{\circ} \mathrm{C}$. No appreciable change was found in the calibration characteristics of both electrodes over the temperature range covered. These observations indicate the high thermal stability of these electrodes.

\section{Effect of other ions}

Selectivity is a salient feature of an ion-selective electrode (ISE) and is considered its primary characteristic as it is constructed to do [41]. The selectivity of an ISE is quantitatively related to equilibria at the interface between the sample and the electrode. The response of an electrode is generally affected by the presence of other ions in solution, and the Nernst equation should be modified to the simplified NicolskyEisenman equation [42].

Selectivity coefficients depend upon the composition of the paste and may take values ranging from zero (indicating no interference) to greater than unity (where the electrode responds to the interferent more strongly than to the primary species). The selectivities determined by the Eisenman equation are incorrect when two ions of different charges significantly contribute to the emf. Besides, $\mathrm{K}_{\mathrm{II}}$ has different dimensions for different charges of the interfering ion $\mathrm{J}^{\mathrm{z}}$. If the charges are different, an alternative approach, modified separate solution method, is used to determine the selectivity [42]. The electrodes' response towards different cations was tested and measured as described in the experimental section. For example, $\mathrm{K}_{\mathrm{II}}=1.0$ for two ions with equivalent responses. Ions with low $\mathrm{K}_{\mathrm{II}}$ values have less impact and a lower interfering effect on the measured potential. When $\mathrm{K}_{\mathrm{II}}$ values are greater than 1 , the ISE is more responsive to the interfering ion. The resulting values, presented in Table 2, show that these sensors display significantly high selectivity for $\mathrm{Cu}(\mathrm{II})$ over many common inorganic ions. It is noteworthy that the results obtained from the two methods are different. The MSSM produced much better values than those obtained by the SSM, following expectations that the MSSM produces unbiased, thermodynamic selectivity coefficients.

\section{Recovery and Determination of Copper lons in Urine and Serum Samples}

Physiological concentrations of copper in human blood serum range from 1.1-2.4 $\times 10^{-3} \mathrm{M}$. Ceruloplasmin is an enzyme synthesized in the liver and is the main carrier of copper ions in the human blood. Wilson's disease (WD) results from serum deficiency of ceruloplasmin. The progression of this disease leads to a significant increase of free copper ions circulating in the bloodstream and accumulation of copper ions in organs 
Table 2. Selectivity coefficient for electrode A and electrode B

\begin{tabular}{lllll}
\hline \multirow{2}{*}{ Interfering species } & \multicolumn{2}{c}{ Electrode A } & \multicolumn{2}{c}{ Electrode B } \\
\cline { 2 - 5 } & SSM & MSSM & SSM & MSSM \\
\hline $\mathrm{K}(\mathrm{I})$ & $4.14 \times 10^{-6}$ & $1.12 \times 10^{-6}$ & $5.46 \times 10^{-6}$ & $2.15 \times 10^{-6}$ \\
$\mathrm{NH}_{4}(\mathrm{I})$ & $3.51 \times 10^{-6}$ & $1.28 \times 10^{-6}$ & $7.33 \times 10^{-6}$ & $1.48 \times 10^{-6}$ \\
$\mathrm{Na}(\mathrm{I})$ & $4.72 \times 10^{-6}$ & $1.41 \times 10^{-6}$ & $6.78 \times 10^{-6}$ & $2.74 \times 10^{-6}$ \\
$\mathrm{Li}(\mathrm{I})$ & $3.25 \times 10^{-6}$ & $1.77 \times 10^{-6}$ & $3.96 \times 10^{-6}$ & $3.46 \times 10^{-6}$ \\
$\mathrm{Ca}(\mathrm{II})$ & $5.41 \times 10^{-6}$ & $1.98 \times 10^{-6}$ & $7.55 \times 10^{-6}$ & $3.42 \times 10^{-6}$ \\
$\mathrm{Ba}(\mathrm{II})$ & $4.78 \times 10^{-6}$ & $2.13 \times 10^{-6}$ & $8.89 \times 10^{-6}$ & $4.26 \times 10^{-6}$ \\
$\mathrm{Zn}(\mathrm{II})$ & $6.33 \times 10^{-6}$ & $4.15 \times 10^{-6}$ & $9.11 \times 10^{-6}$ & $6.32 \times 10^{-6}$ \\
$\mathrm{Ni}(\mathrm{II})$ & $3.78 \times 10^{-6}$ & $2.42 \times 10^{-6}$ & $8.63 \times 10^{-6}$ & $5.93 \times 10^{-6}$ \\
$\mathrm{Co}(\mathrm{II})$ & $5.19 \times 10^{-6}$ & $2.38 \times 10^{-6}$ & $7.76 \times 10^{-6}$ & $4.11 \times 10^{-6}$ \\
$\mathrm{~Pb}(\mathrm{II})$ & $4.73 \times 10^{-6}$ & $3.22 \times 10^{-6}$ & $6.19 \times 10^{-6}$ & $4.27 \times 10^{-6}$ \\
$\mathrm{Mg}(\mathrm{II})$ & $5.22 \times 10^{-6}$ & $3.17 \times 10^{-6}$ & $6.13 \times 10^{-6}$ & $4.66 \times 10^{-6}$ \\
$\mathrm{Mn}(\mathrm{II})$ & $5.31 \times 10^{-6}$ & $3.77 \times 10^{-6}$ & $7.36 \times 10^{-6}$ & $5.47 \times 10^{-6}$ \\
$\mathrm{Al}(\mathrm{III})$ & $3.31 \times 10^{-6}$ & $1.88 \times 10^{-6}$ & $5.41 \times 10^{-6}$ & $2.93 \times 10^{-6}$ \\
\hline
\end{tabular}

Table 3. Analysis of $\mathrm{Cu}(\mathrm{II})$ in tap water and biological fluids samples using calibration curve method

\begin{tabular}{|c|c|c|c|c|}
\hline Sample & Taken $(\mathrm{M})$ & Found $(\mathrm{M})$ & $\mathrm{X} \%$ & R.S.D.\% \\
\hline \multicolumn{5}{|l|}{ Electrode A } \\
\hline \multirow[t]{3}{*}{ Serum } & $1.96 \times 10^{-5}$ & $1.91 \times 10^{-5}$ & 97.44 & 1.98 \\
\hline & $7.14 \times 10^{-5}$ & $6.93 \times 10^{-5}$ & 97.06 & 2.31 \\
\hline & $1.66 \times 10^{-4}$ & $1.61 \times 10^{-4}$ & 97.00 & 2.67 \\
\hline \multirow[t]{3}{*}{ Urine } & $1.96 \times 10^{-5}$ & $1.92 \times 10^{-5}$ & 97.96 & 2.39 \\
\hline & $7.14 \times 10^{-5}$ & $7.01 \times 10^{-5}$ & 98.18 & 2.14 \\
\hline & $1.66 \times 10^{-4}$ & $1.62 \times 10^{-4}$ & 97.59 & 2.54 \\
\hline \multirow[t]{4}{*}{ Drinking water } & $5.00 \times 10^{-7}$ & $4.97 \times 10^{-7}$ & 99.40 & 1.13 \\
\hline & $5.00 \times 10^{-6}$ & $4.98 \times 10^{-6}$ & 99.60 & 1.04 \\
\hline & $5.00 \times 10^{-4}$ & $5.00 \times 10^{-4}$ & 100.0 & 0.89 \\
\hline & $5.00 \times 10^{-3}$ & $4.99 \times 10^{-3}$ & 99.80 & 0.78 \\
\hline \multicolumn{5}{|l|}{ Electrode B } \\
\hline \multirow[t]{3}{*}{ Serum } & $1.96 \times 10^{-5}$ & $1.89 \times 10^{-5}$ & 96.43 & 2.15 \\
\hline & $7.14 \times 10^{-5}$ & $6.94 \times 10^{-5}$ & 97.20 & 2.33 \\
\hline & $1.66 \times 10^{-4}$ & $1.60 \times 10^{-4}$ & 96.39 & 2.58 \\
\hline \multirow[t]{3}{*}{ Urine } & $1.96 \times 10^{-5}$ & $1.90 \times 10^{-5}$ & 96.94 & 2.11 \\
\hline & $7.14 \times 10^{-5}$ & $6.98 \times 10^{-5}$ & 97.76 & 2.32 \\
\hline & $1.66 \times 10^{-4}$ & $1.62 \times 10^{-4}$ & 97.59 & 2.36 \\
\hline \multirow[t]{4}{*}{ Drinking water } & $5.00 \times 10^{-7}$ & $4.93 \times 10^{-7}$ & 98.60 & 1.45 \\
\hline & $5.00 \times 10^{-6}$ & $4.96 \times 10^{-6}$ & 99.40 & 1.21 \\
\hline & $5.00 \times 10^{-4}$ & $5.00 \times 10^{-4}$ & 100.0 & 1.18 \\
\hline & $5.00 \times 10^{-3}$ & $4.98 \times 10^{-3}$ & 99.60 & 0.93 \\
\hline
\end{tabular}

R.S.D.: relative standard deviation, the number of replicate measurements $=5$; X: recovery

such as the brain, liver, and cornea (Kayser-Fleischer rings) [43]. Basal 24-h urinary excretion of copper in WD is typically greater than $100 \mathrm{~g}(1.6 \mathrm{~mol})$ in symptomatic patients [44]. Therefore, the 24-h urinary excretion of $\mathrm{Cu}(\mathrm{II})$ is measured to aid in diagnosing WD that needs proper chelation therapy. The present electrodes were 
used to determine $\mathrm{Cu}(\mathrm{II})$ in spiked urine and blood serum samples as recovery experiments. Tests showed that the addition of $0.1 \mathrm{~mL}$ urine or blood serum did not affect the further measurement of $\mathrm{Cu}$ (II) in the samples. However, adding $1.0 \mathrm{~mL}$ of the body fluids significantly lowered potential values measured by the electrodes. These observations are in line with expectations based on blood serum and urine properties as fluid extracts from the body that generally contain amino acids and other ligands capable of sequestering $\mathrm{Cu}(\mathrm{II})$. After reaction and consumption of the low added amounts of serum or urine with an equivalent amount of $\mathrm{Cu}(\mathrm{II})$, the rest of the samples show linear response as anticipated. These test results collectively indicate that the present electrodes may be successfully used to determine $\mathrm{Cu}$ (II) in urine and blood serum. The results collected using the calibration curve method are presented in Table 3. Recoveries and R.S.D. values range between $98.18-96.39 \%$ of $\mathrm{Cu}(\mathrm{II})$, and 2.67-1.98, respectively. Therefore, the present sensors are applicable for the quantification of $\mathrm{Cu}$ (II) in urine samples.

\section{Determination of copper ions in drinking water samples}

Similarly, $\mathrm{Cu}(\mathrm{II})$ in drinking water samples was potentiometrically determined using these electrodes as indicators, and the results are presented in Table 3. They have reasonable recovery ranges of $100.0-98.60 \%$ and R.S.D. ranges of $0.78-1.45$, which indicates the electrodes are satisfactory for analysis.

\section{Titration of a copper solution with a standard EDTA solution}

Each of the present electrodes was applied as an indicator in titration of $20.0-\mathrm{mL}$ samples of $1.0 \times 10^{-3} \mathrm{M}$
$\mathrm{Cu}^{2+}$ with a standard $0.01 \mathrm{M}$ EDTA solution. The resulting titration curve is shown in Fig. 7. These electrodes provide accurate means for determination.

\section{Comparison with Other Electrodes}

The performance characteristics of the proposed electrode A and those of some reported carbon paste electrodes are compiled in Table 4 for comparison. The detection limit of electrode $\mathrm{A}$ is lower than those of the other electrodes. In addition, its working range is wider than those of the others [18,26-28]. In brief, electrode A excels the relevant electrodes and is more useful for the intended applications with the aforementioned properties.

\section{- CONCLUSION}

Two competitive newly fabricated $\mathrm{Cu}(\mathrm{II})$-selective carbon paste electrodes have been built, characterized,

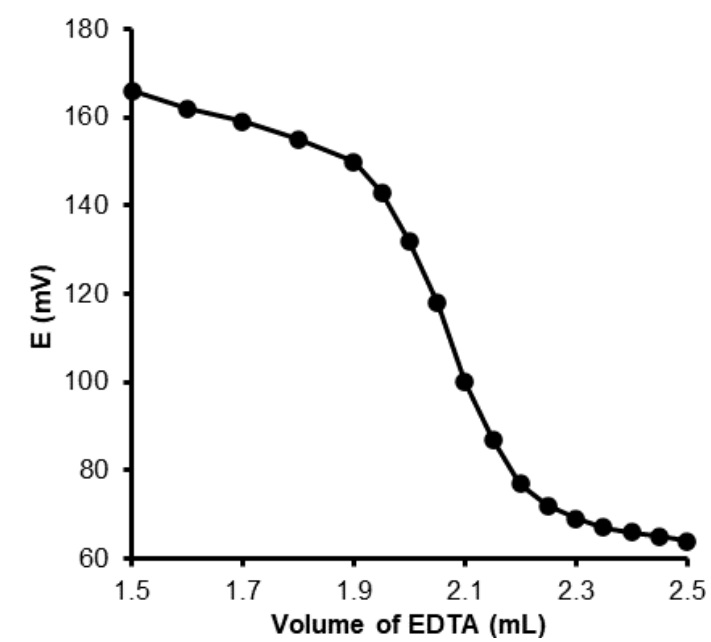

Fig 7. Potential titration curves of $20.0 \mathrm{~mL} 1.0 \times 10^{-3} \mathrm{M}$ $\mathrm{Cu}$ (II) solution with $1.0 \times 10^{-2} \mathrm{M}$ of EDTA of the electrode A

Table 4. Comparison of the proposed $\mathrm{Cu}-\mathrm{CMCPE}$ with reported electrodes

\begin{tabular}{llllll}
\hline Modifier & Slope & C.R. $(\mathrm{M})$ & LOD $(\mathrm{M})$ & $\mathrm{R}(\mathrm{s})$ & Ref. \\
\hline 2-N, N-dimethylcarbamimidoyl (met-formin) & 30.2 & $1.0 \times 10^{-6}-5.0 \times 10^{-2}$ & $3.3 \times 10^{-6}$ & 10 & {$[17]$} \\
2-((3silylpropylaminoethylimino) methyl) phenol in & 29.1 & $5.0 \times 10^{-7}-1.0 \times 10^{-1}$ & $2.5 \times 10^{-7}$ & 15 & {$[28]$} \\
presence of Ag-NP-AC & & & & & \\
CuNiO/Gt nanocomposite & 30.2 & $1.0 \times 10^{-6}-5.0 \times 10^{-2}$ & $1.0 \times 10^{-6}$ & 5 & {$[29]$} \\
(3,4-dihydro-4,4,6-trimethyl-2(1H)-pyrimidine thione & 30.0 & $9.77 \times 10^{-7}-7.6 \times 10^{-2}$ & $7.0 \times 10^{-7}$ & 45 & {$[30]$} \\
etioporphyrin I dihydrobromide & 30.3 & $1.28 \times 10^{-6}-1.28 \times 10^{-2}$ & $8.99 \times 10^{-7}$ & 5 & {$[31]$} \\
2-(furan-2-ylmethyleneamino) phenol & 29.1 & $3.98 \times 10^{-7}-1.00 \times 10^{-2}$ & $2.32 \times 10^{-7}$ & 3 & Present work \\
\hline
\end{tabular}


and tested for applicability. Two Schiff base ligands, 2-((2hydroxybenzylidene)amino) benzoic acid and 2-(furan2-ylmethyleneamino) phenol, were utilized as the ionophores of $\mathrm{Cu}$ (II) based on the distinct stability of these chelating ligands and the flexibility of bonding provided by $\mathrm{Cu}$ (II) over other cations. These sensors have notably good characteristics: low detection limits: $2.32 \times$ $10^{-7}$ and $1.14 \times 10^{-6} \mathrm{M} \mathrm{Cu}(\mathrm{II})$, Nernstian slope of 29.13 and $30.85 \mathrm{mV} /$ decade $\mathrm{Cu}(\mathrm{II})$, wide concentration ranges from $3.98 \times 10^{-7}-1.00 \times 10^{-2}$ and $1.52 \times 10^{-6}-1.00 \times 10^{-2}$ $\mathrm{M}$ for the two sensors, respectively. Also, they have a short response time (ca. $3-5 \mathrm{sec}$ ), distinct $\mathrm{Cu}$ (II) selectivity over other cations, thermal stability up to $50{ }^{\circ} \mathrm{C}$, and applicability over the $\mathrm{pH}$ range 1.5-5.5 for miscellaneous samples. They were proven successful in determining $\mathrm{Cu}$ (II) in aqueous solutions, urine, and blood serum.

\section{- ACKNOWLEDGMENTS}

The authors extend their appreciation to the Deanship of Scientific Research at King Saud University for funding this work through the research group project No. RG-1436-024.

\section{- REFERENCES}

[1] Housecroft, C.E., and Sharpe, A.G., 2012, Inorganic Chemistry, $4^{\text {th }}$ Ed., Pearson Education Limited, Harlow, UK.

[2] Herman, M., Przybylowicz, A., Florek, E., and Piekoszewski, W., 2013, Method of determination of low copper concentration in human hair and nails, $J$. Anal. Chem., 68 (4), 360-367.

[3] WHO, 2019, Water, Sanitation, Hygiene and Health: A Primer for Health Professionals, World Health Organization, Geneva (WHO/CED/PHE/WSH/ 19.149).

[4] Mehrani, Z., Ebrahimzadeh, H., Asgharinezhad, A.A., and Moradi, E., 2019, Determination of copper in food and water sources using poly $\mathrm{m}$ phenylenediamine/CNT electrospun nanofiber, Microchem. J., 149, 103975.

[5] Hassan, M., Erbas, Z., Alshana, U., and Soylak, M., 2020, Ligandless reversed-phase switchablehydrophilicity solvent liquid-liquid microextract-ion combined with flame-atomic absorption spectrometry for the determination of copper in oil samples, Microchem. J., 156, 104868.

[6] Hevia, K., Arancibia, V., and Rojas-Romo, C., 2015, Levels of copper in sweeteners, sugar, tea, coffee and mate infusions. Determination by ad-sorptive stripping voltammetry in the presence of $\alpha$-lipoic acid, Microchem. J., 119, 11-16.

[7] Członkowska, A., Litwin, T., Dusek, P., Ferenci, P., Lutsenko, S., Medici, V., Rybakowski, J.K., Weiss, K.H., and Schilsky, M.L., 2018, Wilson disease, Nat. Rev. Dis. Primers, 4 (1), 21.

[8] WHO, 2004, Copper in Drinking-water. Background document for development of WHO Guidelines for Drinking-water Quality, World Health Organization, Geneva (WHO/SDE/WSH/03.04/88).

[9] Ghaebi, M., and Saadati, M., 2016, Abundance determination of copper in the soil of mine sungun using Neutron activation analysis, J. Radiat. Nucl. Technol., 1 (3), 29-34.

[10] Escárate, P., Hein, R., Durán, M., and Ramaciotti, P., 2015, X-ray fluorescence spectroscopy for accurate copper estimation, Miner. Eng., 71, 13-15.

[11] Payehghadr, M., and Nourifard, F., 2017, Determination of ultra trace copper in water samples by differential pulse polarography after solid phase extraction, Orbital: Electron. J. Chem., 9 (5), 354-359.

[12] Liu, Y., Liang, P., and Guo, L., 2005, Nanometer titanium dioxide immobilized on silica gel as sorbent for pre-concentration of metal ions prior to their determination by inductively coupled plasma atomic emission spectrometry, Talanta, 68 (1), 2530.

[13] Zhong, W.S., Ren, T., and Zhao, L.J., 2016, Determination of $\mathrm{Pb}$ (Lead), Cd (Cadmium), $\mathrm{Cr}$ (Chromium), $\mathrm{Cu}$ (Copper), and $\mathrm{Ni}$ (Nickel) in Chinese tea with high-resolution continuum source graphite furnace atomic absorption spectrometry, $J$. Food Drug Anal., 24 (1), 46-55.

[14] Behbahani, M., Bide, Y., Salarian, M., Niknezhad, M., Bagheri, S., Bagheri, A., and Nabid, M.R., 2014, The use of tetragonal star-like polyaniline 
nanostructures for efficient solid phase extraction and trace detection of $\mathrm{Pb}$ (II) and $\mathrm{Cu}$ (II) in agricultural products, sea foods, and water samples, Food Chem., $158,14-19$.

[15] Ebrahimzadeh, H., Behbahani, M., Yamini, Y., Adlnasab, L., and Asgharinezhad, A.A., 2013, Optimization of $\mathrm{Cu}(\mathrm{II})$-ion imprinted nanoparticles for trace monitoring of copper in water and fish samples using a Box-Behnken design, React. Funct. Polym., 73 (1), 23-29.

[16] Behbahani, M., Salarian, M., Amini, M.M., Sadeghi, O., Bagheri, A., and Bagheri, S., 2013, Application of a new functionalized nanoporous silica for simultaneous trace separation and determination of $\mathrm{Cd}(\mathrm{II}), \mathrm{Cu}(\mathrm{II})$, $\mathrm{Ni}(\mathrm{II})$, and $\mathrm{Pb}(\mathrm{II})$ in food and agricultural products, Food Anal. Methods, 6 (5), 1320-1329.

[17] Barache, U.B., Shaikh, A.B., Lokhande, T.N., Kamble, G.S., Anuse, M.A., and Gaikwad, S.H., 2018, An efficient, cost effective, sensing behaviour liquid-liquid extraction and spectrophotometric determination of copper(II) incorporated with 4-(4'chlorobenzylideneimino)-3-methyl-5-mercap- to1,2,4-triazole: Analysis of food samples, leafy vegetables, Spectrochim. Acta A, 189, 443-453.

[18] Frag, E.Y., Mohamed, M.E.B., and Fahim, E.M., 2018, Application of carbon sensors for potentiometric determination of copper(II) in water and biological fluids of Wilson disease patients. Studying the surface reaction using SEM, EDX, IR and DFT, Biosens. Bioelectron., 118, 122-128.

[19] Tutulea-Anastasiu, M., Wilson, D., del Valle, M., Schreiner, C., and Cretescu, I., 2013, A Solid-contact ion selective electrode for copper(II) using a succinimide derivative as ionophore, Sensors, 13 (4), 4367-4377.

[20] Ansari, R., Mosayebzadeh, Z., Arvand, M., and Mohammad-khah, A., 2013, A potentiometric solid state copper electrode based on nanostructure polypyrrole conducting polymer film doped with 5sulfosalicylic acid, J. Nanostruct. Chem., 3 (1), 33.

[21] Birinci, A., Eren, H., Coldur, F., Coskun, E., and Andac, M., 2016, Rapid determination of trace level copper in tea infusion samples by solid contact ion selective electrode, J. Food Drug Anal., 24 (3), 485492.

[22] Topcu, C., Lacin, G., Yilmaz, V., Coldur, F., Caglar, B., Cubuk, O., and Isildak, I., 2018, Electrochemical determination of copper(II) in water samples using a novel ion-selective electrode based on a graphite oxide-imprinted polymer composite, Anal. Lett., 51 (12), 1890-1910.

[23] Abu Ghalwa, N., Abed Almonem, K.I., Al-Kashef, I.D., Saadeh, S.M., and Abu Shawish, H.M., 2020, Comparative effects of surfactants on the behavior of an anticancer drug potentiometric sensor, Anal. Methods, 12 (5), 679-686.

[24] Abu Shawish, H.M., Abu Ghalwa, N., Al-Kashef, I.D., Saadeh, S.M., and Abed Almonem, K.I., 2020, Extraordinary enhancement of a 5-fluorouracil electrode by praepagen HY micellar solutions, Microchem. J., 152, 104316.

[25] Rouhani, M., and Soleymanpour, A., 2019, A new selective carbon paste electrode for potentiometric analysis of olanzapine, Measurement, 140, 472-478.

[26] Ghaedi, M., Naderi, S., Montazerozohori, M., Taghizadeh, F., and Asghari, A., 2017, Chemically modified multiwalled carbon nanotube carbon paste electrode for copper determination, Arabian J. Chem., 10, S2934-S2943.

[27] Frag, E.Y., and Abdel Hameed, R.M., 2019, Preparation, characterization and electro-chemical application of $\mathrm{CuNiO}$ nanoparticles supported on graphite for potentiometric determination of copper ions in spiked water samples, Microchem. J., 144, 110-116.

[28] Issa, Y.M., Ibrahim, H., and Shehab, O.R., 2012, New copper(II)-selective chemically modified carbon paste electrode based on etioporphyrin I dihydrobromide, J. Electroanal. Chem., 666, 11-18.

[29] Mazzoni, R., Roncaglia, F., and Rigamonti, L., 2021, When the metal makes the difference: Template syntheses of tridentate and tetradentate salen-type schiff base ligands and related complexes, Crystals, 11 (5), 483.

[30] Yuan, X., Chai, Y., Yuan, R., Zhao, Q., and Yang, C., 2012, Functionalized graphene oxide-based carbon 
paste electrode for potentiometric detection of copper ion(II), Anal. Methods, 4 (10), 3332-3337.

[31] Govindaraj, V., Ramanathan, S., and Murgasen, S., 2018, Synthesis, characterization, antibacterial, antifungal screening and cytotoxic activity of Schiff base nickel(II) complexes with substituted benzylidine aminobenzoic acid, Chem. Sin., 9 (3), 736-745.

[32] Chaudhary, N., 2013, In vitro antibacterial studies of some transition metal complexes of Schiff base derived from 2-aminophenol and furan-2carbaldehyde, Arch. Appl. Sci. Res., 5 (6), 227-231.

[33] Egorov, V.V., Zdrachek, E.A., and Nazarov, V.A., 2014, Improved separate solution method for determination of low selectivity coefficients, Anal. Chem., 86 (8), 3693-3696.

[34] Radu, A., Peper, S., Bakker, E., and Diamond, D., 2007, Guidelines for improving the lower detection limit of ion-selective electrodes: A systematic approach, Electroanalysis, 19 (2-3), 144-154.

[35] Bhat, V.S., Ijeri, V.S., and Srivastava, A.K., 2004, Coated wire lead(II) selective potentiometric sensor based on 4-tert-butylcalix[6]arene, Sens. Actuators, B, 99 (1), 98-105.

[36] Ramezani, S., Mashhadizadeh, M.H., Ghobadi, M., and Jalilian, S., 2016, Silica gel/gold nanoparticles/(NS)2 ligand nanoporous platformmodified ionic liquid carbon paste electrode for potentiometric ultratrace assessment of $\mathrm{Ag}(\mathrm{I})$, Int. J. Environ. Sci. Technol., 13 (9), 2175-2188.

[37] Zayed, M.A., Mahmoud, W.H., Abbas, A.A., Ali, A.E., and Mohamed, G.G., 2020, A highly sensitive, selective and renewable carbon paste electrode based on a unique acyclic diamide ionophore for the potentiometric determination of lead ions in polluted water samples, RSC $A d v$., 10 (30), 1755217560.

[38] Pechenkina, I.A., and Mikhelson, K.N., 2015, Materials for the ionophore-based membranes for ion-selective electrodes: Problems and achievements (review paper), Russ. J. Electrochem., 51 (2), 93-102.

[39] García-España, E., Belda, R., González, J., Pitarch, J., and Bianchi, A., 2012, "Receptors for Nucleotides" in Supramolecular Chemistry: From Molecules to Nanomaterials, John Wiley \& Sons, Ltd, Chichester, UK.

[40] Švancara, I., Vytřas, K., Kalcher, K., Walcarius, A., and Wang, J., 2009, Carbon paste electrodes in facts, numbers, and notes: A review on the occasion of the 50-years jubilee of carbon paste in electrochemistry and electroanalysis, Electroanalysis, 21 (1), 7-28.

[41] Ibupoto, Z.H., Khun, K., and Willander, M., 2013, A selective iodide ion sensor electrode based on functionalized $\mathrm{ZnO}$ nanotubes, Sensors, 13 (2), 1984-1997.

[42] Bakker, E., Pretsch, E., and Bühlmann, P., 2000, Selectivity of potentiometric ion sensors, Anal. Chem., 72 (6), 1127-1133.

[43] Blicharska, B., Witek, M., Fornal, M., and MacKay, A.L., 2008, Estimation of free copper ion concentrations in blood serum using T1 relaxation rates, J. Magn. Reson., 194 (1), 41-45.

[44] Brewer, G.J., Gow, P.J., Smallwood, R.A., Angus, P.W., Sewell, R.B., Smith, A.L., and Wall, A.J., 2002, Diagnosis of Wilson's disease: An experience over three decades, Gut, 50 (1), 136-136. 